\title{
Degradação de fitofisionomias do Cerrado e impactos erosivos hídricos lineares no sudoeste de Goiás - Brasil
}

\section{Degradation of Phytophysiognomies of Cerrado and linear water erosive impacts in southwest of Goiás - Brazil}

\author{
Elizon Dias Nunes ${ }^{1}$ \\ Selma Simões de Castro ${ }^{2}$
}

\begin{abstract}
Palavras-chave:
Cobertura e Uso do

Solo

Impacto Ambiental

Análise Multitemporal

Erosão Linear

Resumo

Mudanças na cobertura e uso do solo vêm se tornando um dos principais fatores de degradação ambiental, especialmente na forma de erosão dos solos. Neste contexto, nas últimas quatro décadas os ambientes de Cerrado passaram por intenso processo de conversão da cobertura vegetal em uso antrópico, em especial agricultura, solo exposto e, principalmente, pastagem. O objetivo deste trabalho é avaliar a relação entre essas mudanças e os processos erosivos hídricos, ressaltando as fitofisionomias mais afetadas e o consequente surgimento de áreas críticas quanto a degradação. A metodologia compreendeu a correlação entre a dinâmica do fator CP (cobertura/uso e práticas de manejo) de cada classe de fitofisionomia e uso de 1985 a 2014 e a densidade de focos e respectiva área de contribuição erosiva em 2014. Os resultados indicam que o período 1985-1995 foi marcado pela conversão de Cerradão, Cerrado Ralo e Cerrado Típico em Agricultura, Solo Exposto e Pastagem e no período 1995 2005 houve consolidação desses tipos de uso. No período 2005-2014 houve pouca conversão de fitofisionomias e aumento da consolidação por uso antrópico. As áreas com elevada densidade de focos, de até $3,5 / \mathrm{km}^{2}$, e elevado percentual de contribuição erosiva de até $48 \%$, bem como aquelas em estágios críticos de degradação estão associadas à conversão dessas três fitofisionomias para Solo Exposto e, principalmente, Pastagem, ambos de elevados valores CP. Em todo o período 53,32 \% da área de contribuição erosiva resultaram deste mesmo tipo de conversão e outros 33,88 \% ocorreram em áreas nas quais em 1985 já predominavam esses mesmos tipos de uso e que permaneceram nessa condição por todo o período analisado.
\end{abstract}

\section{Keywords:}

Land cover and Use Environmental Impact Multitemporal Analysis Linear Erosion

\begin{abstract}
Changes in soil cover and use have become a leading environmental degradation factor, especially soil erosion. In the last four decades, Cerrado environments have undergone an intense conversion to anthropic use, especially agriculture, bare soil and, mainly, pasture. This work evaluates the relationship between these changes and water erosion, highlighting the most affected phytophysiognomies and the consequent emergence of critically degraded areas. The methodology comprises the correlation between the CP factor dynamics (Land cover and use and management practices) of each phytophysiognomy class and land use from 1985 to 2014 and the density of outbreaks and area of erosive contribution in 2014. The results indicate that the period 1985-1995 was noteworthy for converting Savannah, Thin Savanna, and Typical Savanna to Agriculture, Bare Soil and Pasture, while the period 19952005, consolidated this type of use. In 2005-2014 there was a low conversion of phytophysiognomies and consequently increased consolidation by anthropic use. The areas with a high density of up to $3.5 / \mathrm{km}^{2}$, a high percentage of erosive contribution (up to $48 \%$ ), and in critical stages of degradation are associated with converting these three phytophysiognomies to Bare Soil and mainly Pasture, both of high CP values. Throughout the period, $53.32 \%$ of the erosive contribution area was due to the same type of conversion. Another $33.88 \%$ occurred in areas where similar use already prevailed in 1985 and persisted in this condition all through the analyzed period.
\end{abstract}




\section{INTRODUÇÃO}

Mudanças na cobertura e uso da terra induzidas por ações antrópicas vêm se tornando um dos fatores que mais contribui, direta e indiretamente, para alterações ambientais mais profundas e severas, cujas consequências podem se refletir desde a escala local até a global (CAPITANI et al., 2016; ELLIS, 2015). Essas alterações resultam de mecanismos de feedback relacionados a essas conversões e que implicam na distribuição e no balanço de energia, sobretudo térmica e cinética, e sua interação com as superfícies continental e oceânica (FINDELL et al., 2017). Com isso, impactos podem ser sentidos na biodiversidade, no clima, na disponibilidade e na qualidade dos recursos naturais, em especial solo e água, na economia e, sobretudo, no bem-estar das populações (ARNOUS et al., 2017; BAJOCCO et al., 2012; GRIGGS et al., 2014).

Nas últimas décadas o gradativo aumento da perda de solos, especialmente em grandes áreas, vem se tornando uma das principais causas da degradação ambiental (HASSAN et al., 2016; ÖZŞAHIN et al., 2018; ÖZŞAHIN; UYGUR, 2014). Esse quadro tem colocado em evidência um grande desafio relacionado ao uso e manejo sustentável dos recursos da superfície terrestre pelas sociedades contemporâneas, a fim de garantir um legado mais justo às gerações futuras. Neste mesmo sentido, ressalta-se os processos de degradação já irreversíveis em muitos casos, bem como os grandes passivos ambientais gerados ao longo de décadas de uso e manejo inapropriado, cujas possibilidades de recuperação são cada vez mais incertas.

As formações vegetais características dos Cerrados recobriam, essencialmente, o Planalto Central brasileiro, compreendendo assim, uma extensa área com uma das mais diversificadas paisagens e biodiversidade do planeta. No início da década de 1950 o principal uso consistia na criação extensiva de gado bovino, sendo que, a partir da década de 1960, esses ambientes passaram a vivenciar uma nova fase de mudanças impulsionada pela modernização da agricultura e, mais recentemente, com a implantação de complexos agroindustriais (GRAZIANO DA SILVA, 1996). Neste contexto, nas últimas décadas a região dos Cerrados vem passando por significativas mudanças na cobertura e uso do solo, ganhando novos significados, sobretudo econômico. Dessa forma, a mesma se tornou uma região estratégica para o agronegócio em função da localização e do relevo em grande parte favorável ao manejo agrícola por processos mecanizados (OLIVEIRA, 2014; SILVA et al., 2015).

A chegada da fronteira agrícola contou com incentivos públicos associados a disponibilidade de extensas áreas de chapadões com condições climáticas e pedológicas favoráveis ao desenvolvimento de atividades agrícolas durante a maior parte do ano. Isto provocou ondas migratórias, sobretudo, das regiões Sul e Sudeste do Brasil, devido a facilidade de aquisição de extensas áreas a preços muito baixos. As mudanças se intensificaram a partir da implantação de programas governamentais, especialmente vinculados ao I PND (Plano Nacional de Desenvolvimento) (1972-1974), como o PRODOESTE (Programa de Desenvolvimento do Centro-Oeste) e ao II PND (1975-1979), como o POLOCENTRO (Programa de Desenvolvimento dos Cerrados) e o PRODECER (Programa de Cooperação NipoBrasileira para o Desenvolvimento Agrícola dos Cerrados), com o intuito de promover o desenvolvimento e a integração da região ao sistema produtivo nacional como lembraram Barbalho e Castro (2014); Menezes et al. (2009); Oliveira et al. (2018) e Rocha et al. (2014).

No entanto, a falta de estudos sistematizados acerca das potencialidades e limitações de cada ambiente face às formas de uso e práticas de manejo então aplicadas resultou em situações de elevado estágio de degradação, principalmente por meio de processos erosivos hídricos lineares envolvendo ravinas e voçorocas. Neste sentido, o objetivo geral do presente trabalho é avaliar a relação entre o processo de conversão de fitofisionomias de Cerrado para uso antrópico e a ocorrência de feições erosivas hídricas lineares com o consequente surgimento de áreas críticas caracterizadas pela elevada densidade de focos e área de contribuição erosiva, ressaltando as fitofisionomias mais degradadas no período de 1985-2014.

\section{MATERIAIS E MÉTODO}

\section{Localização e caracterização da área de estudo}

A área de estudo abrange os municípios de Mineiros, Santa Rita do Araguaia, Perolândia e Portelândia, todos localizados na Microrregião Sudoeste de Goiás e situados nas partes mais elevadas das bacias dos rios Araguaia e Paranaíba (Figura 1). O substrato geológico corresponde à Bacia Sedimentar do Paraná 
composta, predominantemente, por formações sedimentares diversas com o predomínio de argilitos, arenitos e depósitos de areia, por vezes, permeadas por intrusões basálticas. Tais formações, como especificado a seguir, apresentam diferentes resistências aos processos de intemperismo, o que resulta em diversos patamares altimétricos correspondentes a superfícies geomórficas escalonadas. Como destaque tem-se o topônimo Serra de Caiapó, o qual faz parte do Planalto Setentrional da Bacia do Paraná (AB' SABER; COSTA JÚNIOR, 1950; DRAGO et al., 1981), sendo que sua porção mais elevada pode atingir altitudes de até $1010 \mathrm{~m}$.

Figura 1 - Localização da área (a); Formações Geológicas e litologias (b); Hipsometria (c); Declividade (d); pedologia (e); e cobertura e uso do solo em 2014 (f).

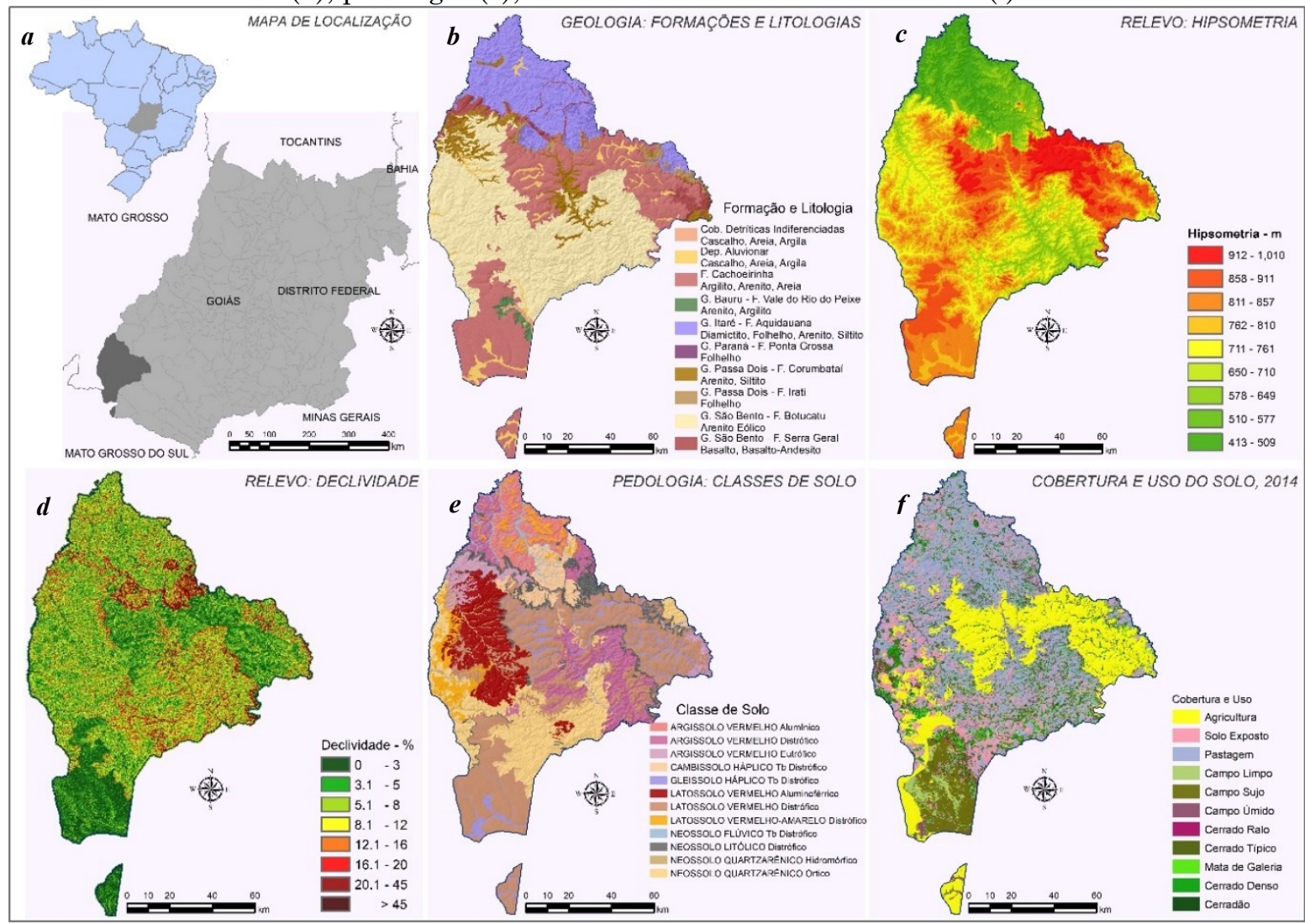

Fonte: Nunes (2015).

Os diversos patamares altimétricos apresentam limites bem estabelecidos, uma vez que a transição para as áreas adjacentes é marcada pela nítida redução das altitudes, acompanhada pelo aumento das declividades. Trata-se de uma consequência direta de mudanças na litologia que, por sua vez, influencia os padrões geomorfológicos, pedológicos e, principalmente, de cobertura e uso do solo, com reflexos diretos nos impactos relacionados aos processos erosivos hídricos lineares.

As superfícies mais elevadas e planas, como na porção central e no extremo sul da área, são sustentadas por argilitos, arenitos e depósitos de areia pertencentes à Formação Cachoeirinha (BRASIL, 1983; LACERDA FILHO; FRASCA, 2008). Nestas, as altitudes variam de 857 a 1010 $\mathrm{m}$, com a declividade variando de 0 a $8 \%$, configurando extensos planaltos denominados de Chapadas ou Chapadões. Neles predomina o Latossolo Vermelho de textura argilosa a muito argilosa em declives de até 8\%, e Gleissolo Háplico de textura argilosa ao longo das planícies acompanhando os canais de baixo gradiente altimétrico e declive de até $3 \%$ (ALVES, et al., 2017; PAULINO et al., 2015). As áreas de Latossolo foram as primeiras a serem ocupadas por agricultura ainda na década de 1960, cuja consolidação se deu na década de 1970, com o advento da modernização da agricultura (PINTO; WANDER, 2016), atrelada à chamada Revolução Verde, envolvendo elevada aplicação de conhecimento tecnológico no manejo das terras.

Nas porções oeste e sudeste predominam arenitos eólicos do Grupo São Bento - Formação Botucatu, entremeados por arenitos e siltitos do 
Grupo Passa Dois - Formação Corumbataí (BRASIL, 1983). A primeira encontra-se em patamares mais elevados e preservados, com interflúvios de bordas mais arredondadas e predomínio de Latossolo Vermelho de textura média associado a Neossolo Quartzarênico Órtico de textura arenosa que transicionam para Neossolo Quartzarênico Hidromórfico nos fundos de vale, por vezes sedimentados/assoreados. Os usos predominantes são agricultura em áreas de Latossolos e pastagem em áreas de solos com menor fertilidade como os Neossolos arenosos.

$\mathrm{Na}$ porção sudeste, mais rebaixada e dissecada, e com interflúvios mais concavizados predomina o Argissolo Vermelho de textura média e, principalmente, Neossolo Quartzarênico Órtico de textura arenosa (SCOPEL et al., 2013). São áreas onde o processo de conversão para uso antrópico se intensificou ao longo da década de 1970 e principalmente 1980. A baixa aptidão para agricultura promoveu a conversão de extensas áreas em pastagem e, recentemente, áreas de solo exposto, sobre os quais avançam os processos erosivos hídricos lineares (NUNES; CASTRO, 2015).

$\mathrm{Na}$ porção norte predominam diamictitos, folhelhos, arenitos e siltitos pertencentes ao Grupo Itaré, Formação Aquidauana (BRASIL, 1983; MOREIRA, et al., 2008). Trata-se da área ainda mais rebaixada que as anteriores, com altitudes de até $413 \mathrm{~m}$, dissecação erosiva avançada e já aplanada, resultando em baixo gradiente, com declives até $20 \%$ nas bordas de interflúvio e $3 \%$ nos fundos de vale. Nela, predominam Argissolos Vermelhos de textura média que transicionam para Neossolo Flúvico de textura arenosa ao longo dos canais principais. O uso é predominantemente com pastagem, sendo que nos últimos anos vem apresentado expressivas manchas de solo exposto.

Em toda a área o clima é tropical subúmido, com dois períodos bem distintos. Um seco, que vai de junho a agosto, e outro chuvoso, que vai de setembro a maio (SILVA et al., 2006), enquadrando-se no tipo Aw de Köppen (MONTEIRO, 1951; NIMER, 1972).

Mapeamento dos focos e elaboração dos mapas de densidade e área de contribuição erosiva

O mapeamento dos focos erosivos lineares foi realizado a partir da interpretação e inspeção visual de imagens GeoEye coloridas e com resolução espacial de $0,4 \mathrm{~m}$ referentes ao segundo semestre de 2014. Para fins de mapeamento considerou-se como erosão a feição com aspecto linear, ligeiramente aprofundada e com bordas íngremes, e em geral com interior com aspecto degradado e contrastando com o entorno imediato, conforme ilustrado na Figura 2. Nesse nível de detalhamento, escala 1:2.000, foi possível o mapeamento em polígono, o que permitiu calcular o ponto central ou centróide, bem como a área de cada feição posteriormente convertida em área de contribuição erosiva (\% de área erodida em $1 \mathrm{~km}^{2}$, por exemplo) e, por consequência, avaliar de forma mais assertiva o estágio de degradação. A varredura e análise das imagens foi realizada mediante a divisão do polígono envolvente da área de estudos em retângulos com as dimensões 1000 x $500 \mathrm{~m}$, ajustados a um monitor de 21”. Tal procedimento permitiu que toda a área de estudos fosse inspecionada visualmente no mesmo nível de detalhamento, compatível com os parâmetros de resolução da imagem, evitando-se, assim, interpretações e decisões equivocadas acerca da feição erosiva e, principalmente, quanto aos seus limites. Desta forma, foi possível perceber padrões espaciais de ocorrência de focos erosivos de forma mais rigorosa e, em consequência, a possibilidade de classificação dos mesmos em pequeno, médio e grande porte.

Figura 2 - Localização e mapeamento de feições erosivas de médio porte $(a)$; e de feição erosiva de grande porte $(b)$.
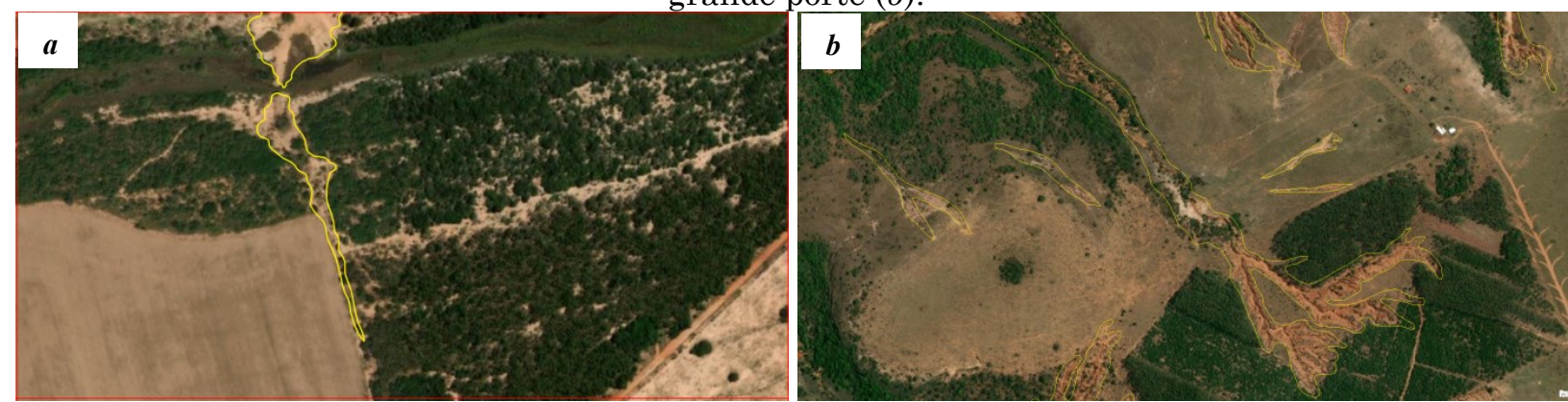

Fonte: os autores (2018). 
Para elaboração dos mapas de densidade de focos e área de contribuição erosiva utilizou-se a densidade de Kernel, ferramenta disponível no software ArcGIS. Para a densidade de focos em ponto adotou-se um raio de análise ou de ponderação de 3700 metros, o que corresponde à distância média entre os centróides das feições erosivas, unidade resultante $\mathrm{n}^{\circ}$ de focos por $\mathrm{km}^{2}$ e resolução de saída de 30 metros em estrutura matricial. Para a realização do mapa de área de contribuição erosiva adotou-se a relação área do foco erosivo/área do entorno, considerando um raio de análise de 700 metros, o que corresponde a distância média entre as bordas das feições erosivas, obtendo dessa forma, a dimensão percentual de área de contribuição erosiva também em estrutura matricial e com resolução espacial de saída de 30 metros.

A elaboração do mapa bivariado de áreas críticas se deu mediante a divisão e cruzamento das cinco classes de cada parâmetro, resultando assim em uma legenda 5x5 classes. Esse procedimento permitiu uma representação detalhada de quatro diferentes padrões de ocorrência erosiva da área, quais sejam: baixa densidade de focos $\left(0-0,5\right.$ foco $\left./ \mathrm{km}^{2}\right)$ e baixa área de contribuição erosiva ( 0 - $5 \%$ \%); baixa densidade de focos e alta área de contribuição erosiva (20 - $48 \%$ ); alta densidade de focos (2 3,5 focos $/ \mathrm{km}^{2}$ ) e baixa área de contribuição erosiva; e áreas extremamente críticas paras as quais tanto a densidade de focos quanto a área de contribuição erosiva são elevadas.

Mapeamento multitemporal das classes de cobertura e uso e sua correspondência em fator CP (Cobertura e Práticas de Manejo).

O mapeamento das classes de fitofisionomias e uso do solo foi elaborado a partir de imagens Landsat correspondentes aos meses sem chuva. Para os anos de 1985, 1995 e 2005 utilizou-se imagens do sensor TM Landsat 5 na composição colorida RGB 543 e realce espectral de $2 \%$. Já para o ano de 2014 utilizou-se o sensor e OLI Landsat 8 na composição RGB 654 e mesmo realce. A definição das classes de fitofisionomias seguiu a nomenclatura proposta por Ribeiro e Walter (2008), a qual contempla as principais fitofisionomias presentes nas formações vegetais do bioma Cerrado (Formações Florestais, Savânicas e Campestres) (Figura 3).

Figura 3 - Fitofisionomias do bioma Cerrado e sua correspondência em cor e textura a partir de imagens TM Landsat 5.

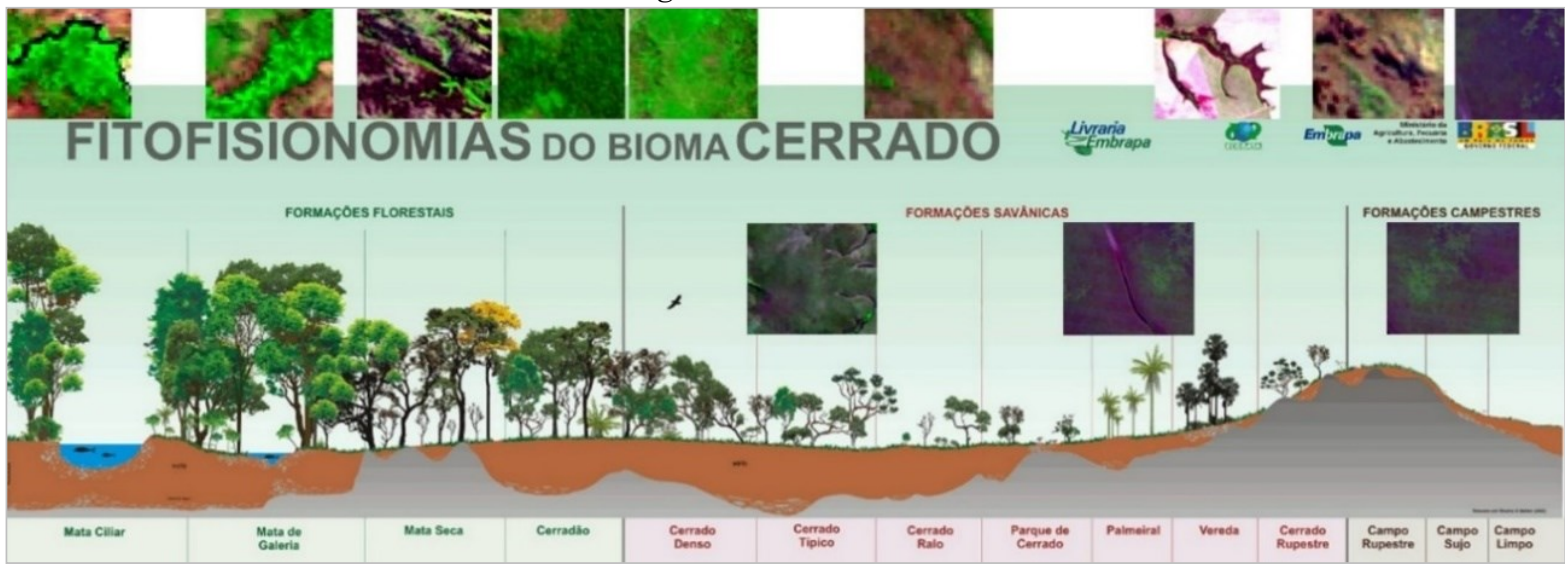

Fonte: adaptado de Ribeiro e Walter (2008).

Para tanto, a chave de classificação foi elaborada a partir da associação entre o inventário feito por meio de fotografias e observações de áreas representativas de cada fitofisionomia em campo, cujas coordenadas foram coletadas com GPS e transpostas para ambiente digital e sobrepostas às imagens, observando a cor e a textura verificadas no entono de cada ponto. Procedimento semelhante foi adotado por Castro (2014) para a identificação de fitofisionomias do bioma Cerrado a partir de aerogamaespectrometria e sensoriamento remoto, permitindo assim um melhor aproveitamento das imagens TM
Landsat 5 na identificação de fisionomias da vegetação.

De posse dos mapas de cobertura e uso e manejo do solo, o passo seguinte foi analisar a correspondência de cada classe com o fator de Uso/Manejo e Práticas Conservacionistas fatores C e P da Equação Universal de Perda de Solos -, segundo Oliveira (2012) e Stein et al. (1987). Em seguida procedeu-se a divisão do intervalo encontrado em cinco classes, atribuindo para cada uma delas um código para relacionar com a respectiva classe dos demais recortes temporais (Tabela 1 ). 
Tabela 1 - Classes de fitofisionomias, cobertura e uso do solo e suas correspondências em Fator C (Cobertura/Uso e Manejo) e P (Práticas Conservacionistas).

\begin{tabular}{l|r|r|r|r}
$\begin{array}{l}\text { Formação Vegetal/Fitofisionomia e } \\
\text { Cobertura e Uso }\end{array}$ & Fator C & Fator P & \multicolumn{1}{|c}{$\begin{array}{c}\text { Fator } \\
\text { CP }\end{array}$} & \multicolumn{2}{|c}{$\begin{array}{c}\text { Código da } \\
\text { Classe }\end{array}$} \\
\hline $\begin{array}{l}\text { Campo Úmido } \\
\text { Cerradão, Cerrado Denso, Mata de }\end{array}$ & 0.00004 & 1 & 0 & 1 \\
Galeria & & 1 & 0.00004 & 2 \\
Cerrado Típico & & & \\
Campo Sujo & 0.0007 & 1 & 0.0007 & 4 \\
Agricultura & 0.12 & 1 & 0.01 & 4 \\
Cerrado Ralo & 0.01035 & 1 & 0.0144 & 4 \\
Campo Limpo & 0.02 & 1 & 0.01035 & 4 \\
Pastagem & 0.1 & 1 & 0.02 & 5 \\
Queimada & 0.2 & 1 & 0.1 & 5 \\
Solo Exposto & 1 & 1 & 1 & 5
\end{tabular}

Fonte: adaptado de Oliveira (2012); Stein et al. (1987).

Tal procedimento permitiu estabelecer relações espaciais bivariadas entre variáveis, bem como entre cada uma destas e o fenômeno relacionado aos processos erosivos. O fluxograma síntese dos materiais utilizados, dos procedimentos metodológicos e respectivos produtos de síntese elaborados, é apresentado na Figura 4.

Figura 4 - Fluxograma síntese dos procedimentos metodológicos adotados.

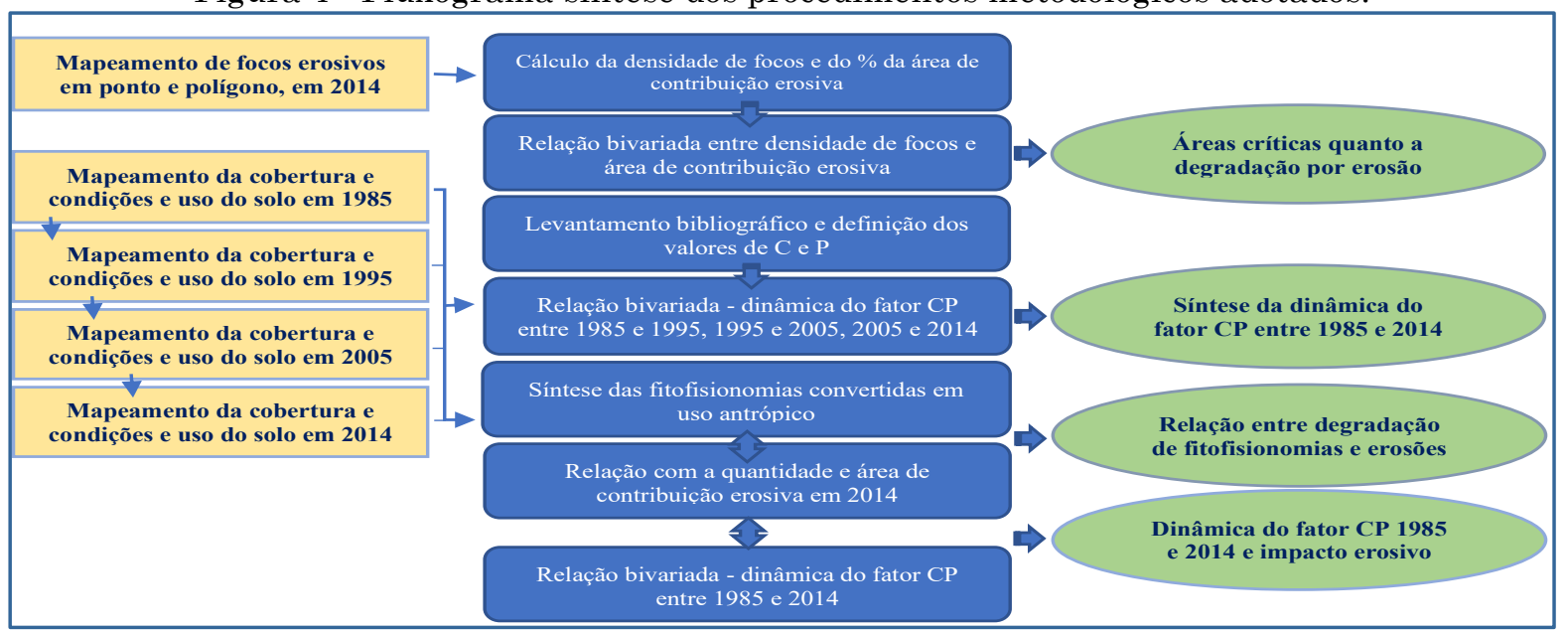

Fonte: adaptado de Nunes (2015).

\section{RESULTADOS E DISCUSSÃO}

\section{Análise bivariada entre as classes de densidade de focos e de área de contribuição erosiva em 2014}

Da análise do mapeamento destacam-se quatro padrões espaciais e numericamente distintos quanto à distribuição das feições erosivas, conforme apresentado na Figura 5. Um resulta da baixa densidade de focos e baixa área de contribuição erosiva, corresponde às áreas de planalto cobertas por Latossolos Vermelhos e, em menor proporção, por Gleissolos Háplicos, ambos de textura argilosa e baixa declividade, cuja consolidação do uso por agricultura ocorreu nas décadas de 1970 e 1980. Além do uso agrícola, outro fator decisivo para tal situação é a existência do Parque Nacional das Emas, cuja vegetação preservada impede a degradação do solo por processos erosivos. 
Figura 5 - Mapas de densidade de focos erosivos em ponto (a); área de contribuição erosiva (b); e relação bivariada entre os dois (c).

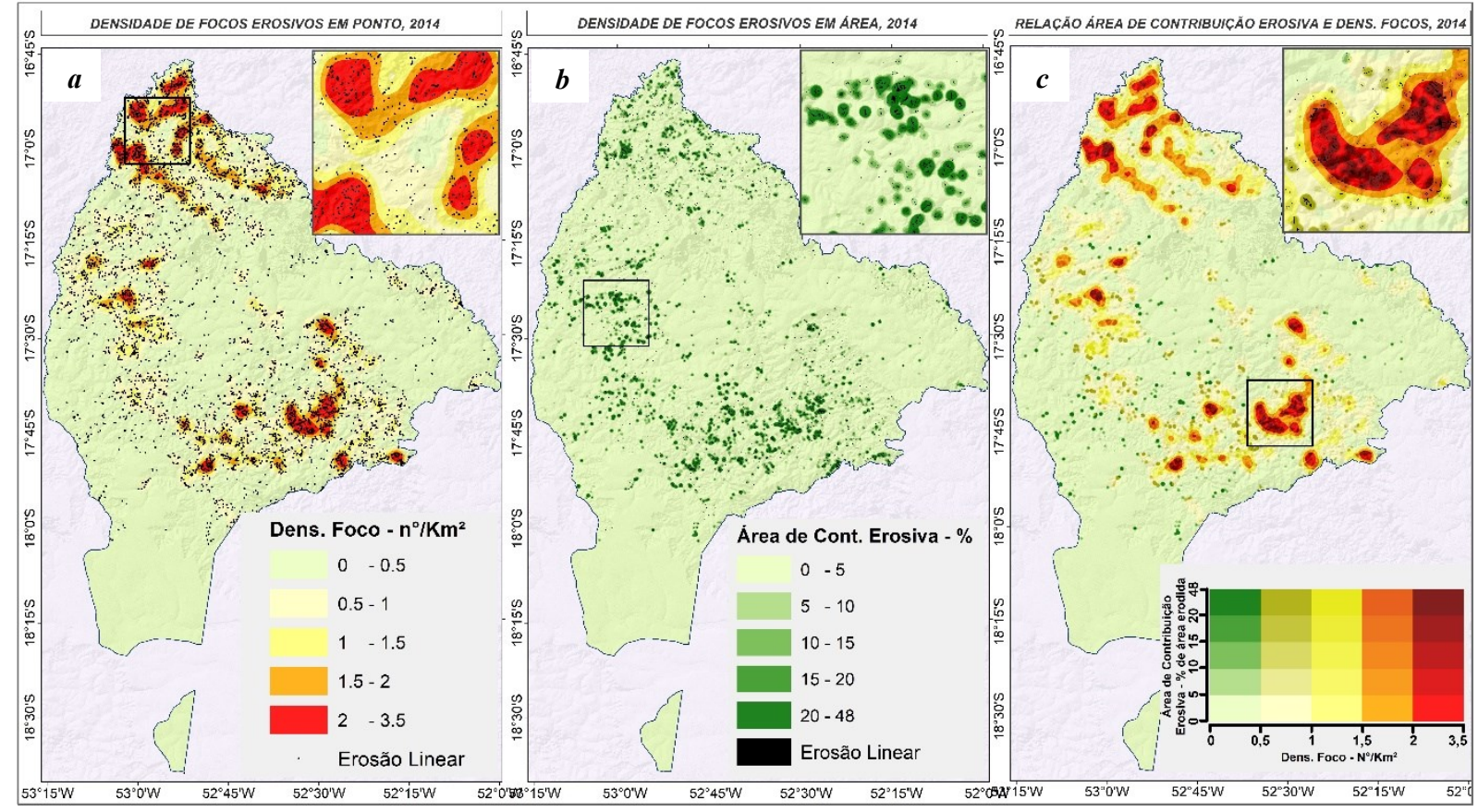

Fonte: adaptado de Nunes (2015).

Outro padrão resulta de áreas com alta densidade de focos e baixa área de contribuição erosiva (detalhe da Figura 5 a), que se concentra na transição das porções central e norte da área de estudo. Corresponde à ambientes com predomínio de Neossolos Litólicos e Cambissolos Háplicos, ambos variando de textura média a cascalhenta, onde a quase totalidade dos focos erosivos possui menos de 1 ha. A impressão de elevada área de contribuição erosiva se deve à elevada quantidade de focos, bem como à elevada proximidade entre as incisões. No entanto, embora esse padrão de distribuição espacial se assemelhe àquele com ocorrência de grandes erosões, a pouca profundidade desses solos proporciona desagregação, predominantemente, nas porções mais superficiais.

Outro padrão resulta de áreas com baixa densidade de focos e elevada área de contribuição erosiva (detalhe da Figura 5 b). Embora ocorra também nas porções norte e sudeste, esse padrão é mais característico da porção oeste, onde o número de focos é pequeno, mas a área de contribuição erosiva tende a ser grande, sendo que 3 dos 18 maiores focos com áreas superiores a 12 ha ocorrem nessa porção. Trata-se de áreas com predomínio de Latossolos Vermelhos de textura média associados à declividades de até $8 \quad \% \quad$ e utilizados predominantemente por agricultura, embora em algumas partes ocorram pastagens. Os grandes focos erosivos tendem a ocorrer quando da passagem do terço superior para o terço intermediário das vertentes e consequente exposição de áreas com a ocorrência de Neossolos Quartzarênicos de textura arenosa oriundos de arenitos eólicos da Formação Botucatu. O desencadeamento de incisões erosivas nesses ambientes está fortemente associada ao uso por pastagem e sua evolução fortemente condicionada pela maior profundidade e textura dos solos, com a perda ocorrendo em grande magnitude na forma de grandes incisões.

Já em relação ao padrão resultante da elevada densidade de focos e elevada área de contribuição erosiva é possível destacar pelo menos 18 áreas em elevado nível de degradação, sendo que destas, 15 ocorrem na porção sudeste, conforme ilustrado na Figura 5 c. Embora ocorram nas porções norte e oeste, os maiores estágios de degradação estão localizados na porção sudeste, onde ocorrem até 3,5 focos a cada $\mathrm{km}^{2}$ e com área de contribuição atingindo $48 \%$. Trata-se de áreas com a ocorrência de Argissolo Vermelho e, principalmente, Neossolos Quartzarênicos, ambos de textura arenosa e associados a declividades variando de 8 a $16 \%$. Para essas áreas o uso por pastagem começou ainda na década de 1970 e, em decorrência da baixa aptidão para agricultura, permaneceram nessa condição ao longo de todo o período. Tal condição resultou em erosões que, devido ao comportamento remontante, chegam a 
ocupar até 25,2 ha de área, atingindo também o substrato rochoso.

\section{Degradação de fitofisionomias e processos erosivos hídricos lineares.}

O resultado do processo de conversão da cobertura vegetal em uso antrópico nos anos de $1985,1995,2005$ e 2014, pode ser conferido na Figura 6. Ao longo de todo o período o uso por agricultura se concentrou nas superfícies mais elevadas e planas, inclusive nas imediações do
Parque Nacional das Emas, ao passo que o surgimento e aumento de áreas de pastagem e solo exposto se concentrou nas áreas mais rebaixadas e dissecadas, onde predominam solos mais arenosos e de menor fertilidade. Tal constatação corrobora as afirmações de Pinto e Wander (2016) e Silva (2018), quando afirmam que as áreas de planaltos foram as primeiras a serem ocupadas pelas culturas anuais, cujo processo de consolidação ocorreu nas décadas de 1970 e 1980.

Figura 6 - Dinâmica espacial e temporal das classes de fitofisionomias e uso do solo no sudoeste de

Goiás nos anos de 1985, 1995, 2005 e 2014.

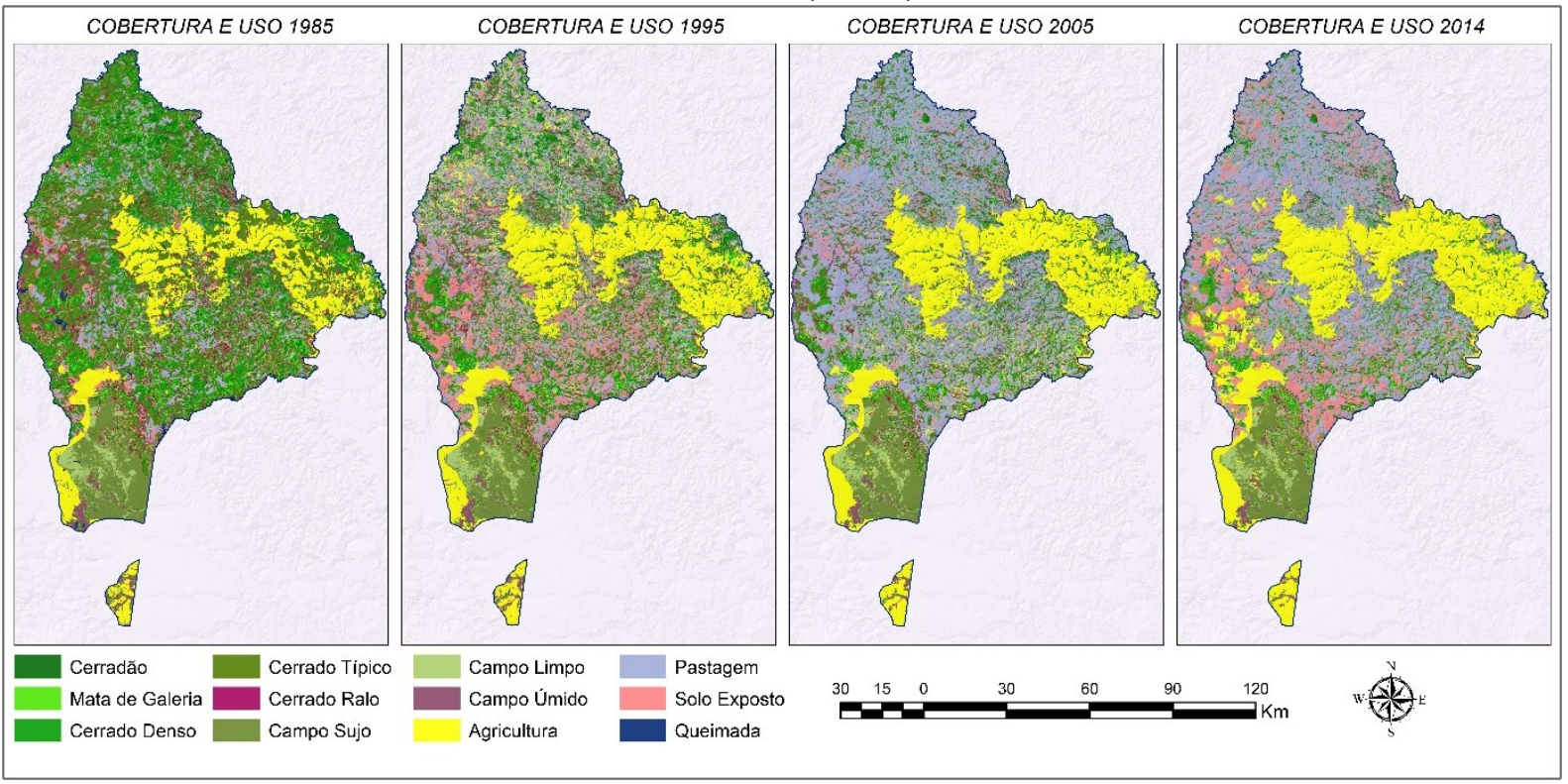

Fonte: Nunes (2015).

$\mathrm{Na}$ área de estudo o mapeamento indica que a maior consolidação ocorreu pouco depois, entre 1985 e 1995, uma vez que foi a partir deste último ano que se observou tendência de estabilização da área ocupada por agricultura, que passou a predominar em cerca de $23,7 \%$ da área.

Em relação às áreas de pastagem e solo exposto observa-se que em 1985 já eram notadas em pequenas, porém numerosas manchas nas porções norte, oeste e sudeste, perfazendo pouco mais de $9,50 \%$ e $4,63 \%$ da área de estudo, respectivamente. Para este mesmo ano e em áreas muito expressivas ocorriam as principais fitofisionomias de Cerrado. Pela ordem de predominância destacam-se: Cerradão 23,32\%; Cerrado Ralo 18,03\%; Campo Sujo 6,63\%; Mata de Galeria 6,24\%; Campo Úmido 6,31\%; Cerrado Típico 4,93\%; Cerrado Denso e Campo Limpo com $2,42 \%$ de ocorrência cada um, conforme demonstrado na Figura 7.

No período 1985-1995 o que se observa é uma acentuada redução da cobertura vegetal em detrimento da expansão das áreas de solo exposto e principalmente pastagem. Das fitofisionomias mais degradadas tem-se o Cerradão, o Cerrado Ralo e o Cerrado Típico que, de $23,32 \%, 18,03 \%$ e $4,93 \%$ em 1985 , passaram a predominar em apenas 10,29\%, 9,89\% e 1,91\%, respectivamente, da área em 1995. Para as demais fitofisionomias, suas áreas pouco foram alteradas. A maior frequência do Campo Limpo e Campo Sujo se relaciona com a proximidade do Parque Nacional das Emas; do Campo Úmido e da Mata de Galeria da maior proximidade dos cursos d'água. 
Figura 7: Dinâmica de cada classe de cobertura e uso do solo em 1985, 1995, 2005 e 2014 e respectivos percentuais de focos e área de contribuição erosiva.

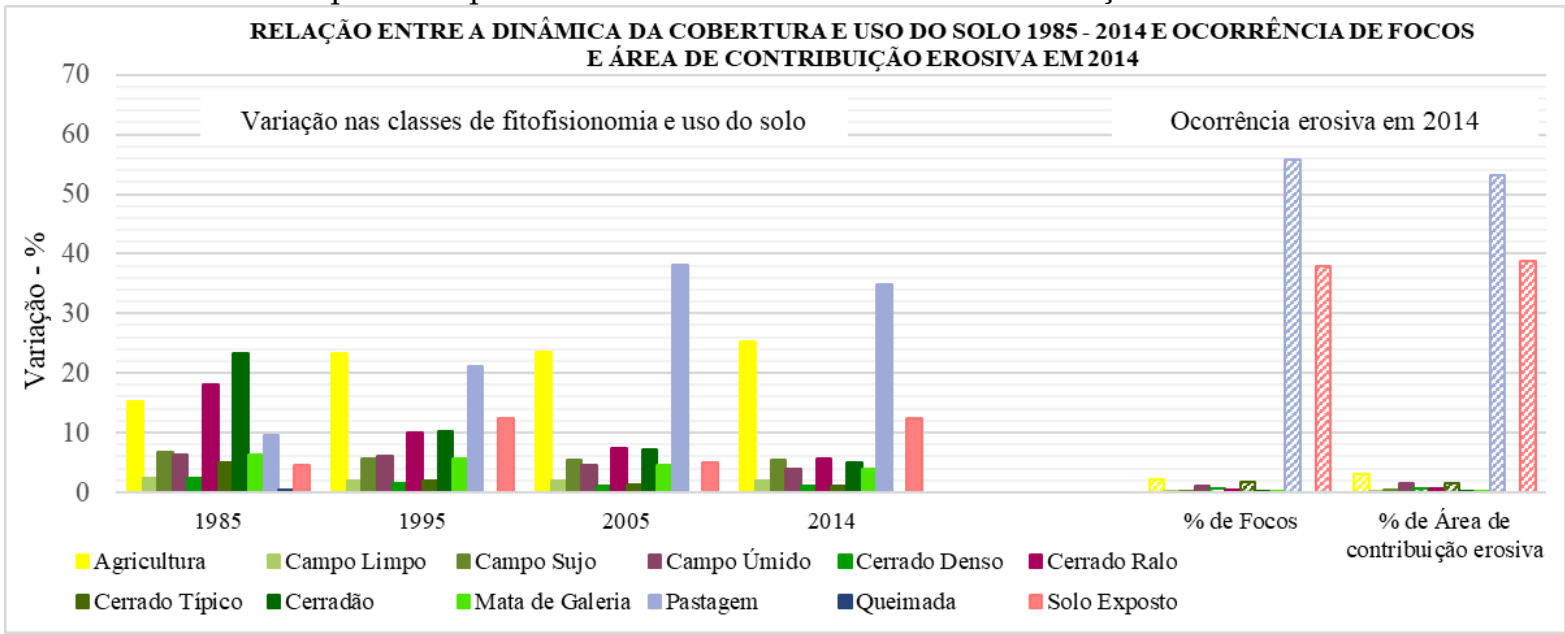

Org.: dos autores (2018).

Nos intervalos 1995-2005 e 2005-2014 o que se constata é a tendência de estabilização das condições de cobertura e uso do solo, com as fitofisionomias, especialmente aquelas de topo de interflúvio e média vertente, reduzindo-se a pequenas manchas, ao passo que solo exposto e, principalmente pastagem, passam a predominar na maior parte da área, sobretudo nos ambientes onde o uso por agricultura sempre foi muito discreto em razão baixa fertilidade do solo.

Em relação aos processos erosivos observa-se que as áreas com solo exposto e principalmente com pastagens foram determinantes para a concentração do fenômeno. Isso porque em 2014, cerca de $38 \%$ das incisões ocorriam associadas a solo exposto, enquanto que $55,8 \%$ ocorriam associados a pastagem, totalizando assim 93,80\%. Trata-se de valores muito expressivos, tal como foi constatado por Barbalho e Castro (2014) que destacam o uso por pastagem como sendo responsável por mais de $60 \%$ dos processos erosivos nas bacias dos rios Claro e dos Bois. Acerca da área de contribuição erosiva o solo exposto apresenta um leve aumento na associação com as incisões, passando para $38,8 \%$, ao passo que as pastagens respondem por $53,1 \%$, perfazendo assim cerca de $91,9 \%$.

\section{Análise bivariada do Fator CP e sua relação com a ocorrância de processos erosivos}

Da análise bivariada da dinâmica do fator $\mathrm{CP}$ ao longo de cada um dos intervalos de 10 anos é possível perceber três situações. Uma, menos recorrente, na qual se constata a redução dos valores $\mathrm{CP}$; outra para qual houve aumento; e outra de maior ocorrência em que os valores CP se mantiveram inalterados. No intervalo 1985 1995 quase nenhum ambiente - apenas 1,43\% apresentou redução do fator CP. Isso fica comprovado pela quase inexistência de áreas em tons azuis na parte $\boldsymbol{a}$ da Figura 8. A razão para a pouca ocorrência de redução em detrimento de uma notável área com aumento do fator CP é que se trata de um período no qual o processo de antropização foi mais acentuado, com extensas áreas de vegetação natural sendo destinadas ao uso por pastagens.

Situação mais frequente refere-se àquela na qual houve aumento do fator $\mathrm{CP}$, resultante da conversão das fitofisionomias Cerrado Denso, Cerrado Típico e Cerrado Ralo em agricultura e, principalmente pastagem e solo exposto, ambos com elevados valores de fator CP. Tal fato é notório pela elevada ocorrência de áreas em tons amarelo e laranja e respectivos percentuais na parte $\boldsymbol{a}$ da Figura 8. Observando todas as classes nessa condição percebe-se que, no período, cerca de $27 \%$ da área mostraram aumento nos valores $\mathrm{CP}$, o que evidencia o fato de que se trata de uma região em considerável processo de conversão da cobertura vegetal para uso antrópico. Já as situações mais presentes $72,28 \%$ da área - referem-se àquelas nas quais não houve alteração na cobertura e principalmente no uso do solo e, em consequência, manutenção do valor CP. 
Figura 8 - Mapas de mudanças no fator CP entre 1985 e 1995 (a); entre 1995 e 2005 (b) e respectivas áreas de ocorrência.

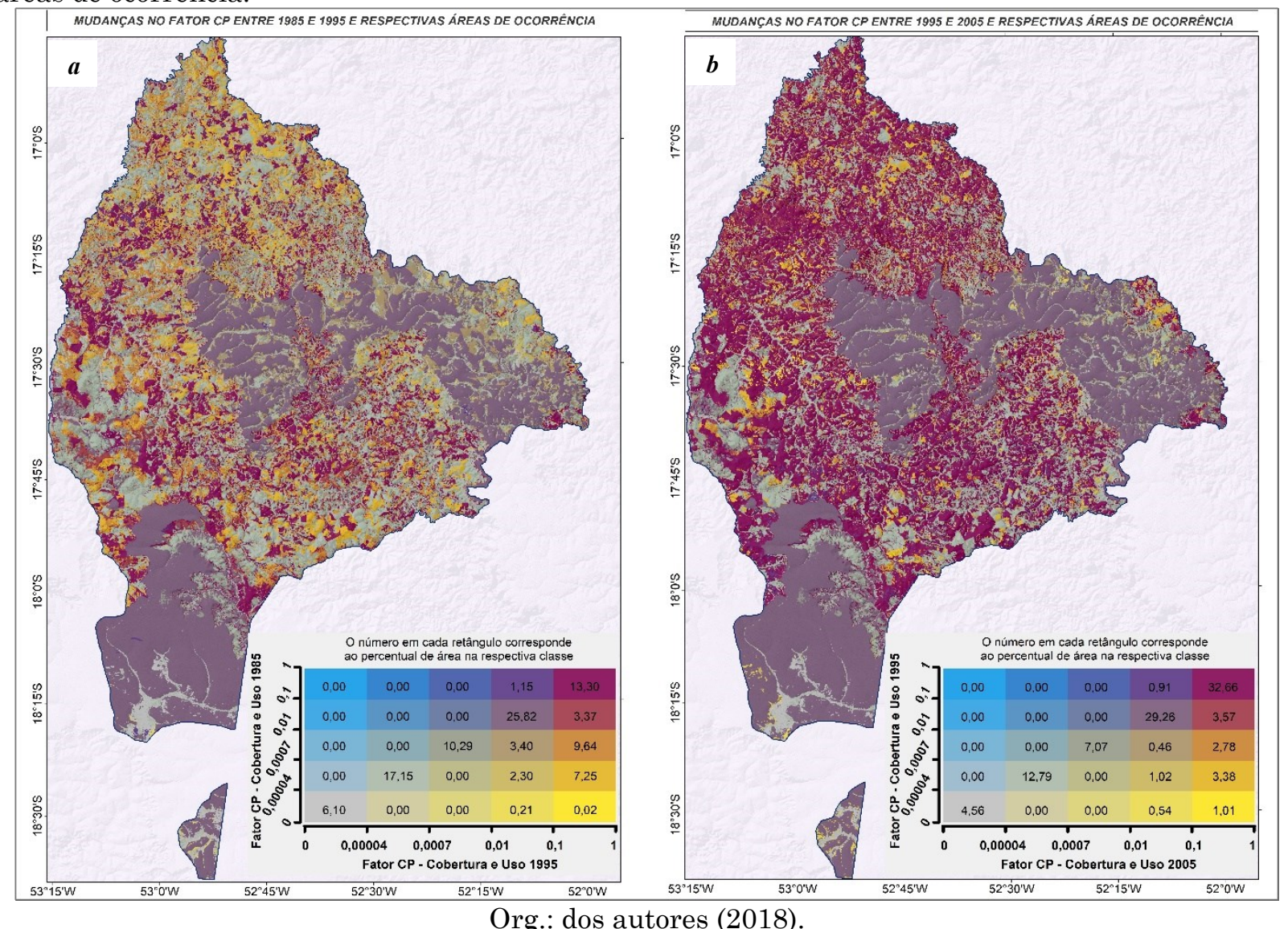

A análise da dinâmica dos valores de fator $\mathrm{CP}$ entre 1995 e 2005 (Figura $8 \boldsymbol{b}$ ) permite perceber que houve um ligeiro aumento de áreas para as quais houve redução do fator CP. De $1,43 \%$, no intervalo 1985 -1995, a mesma passou para $1,59 \%$ na década seguinte, sendo que, deste total, $0,94 \%$ correspondia à reconversão de solo exposto e pastagem para agricultura. Em relação às áreas que tiveram aumento do fator CP, observa-se uma acentuada redução em relação ao período anterior. Observando todas as áreas nessa condição observa-se que em apenas $13,12 \%$ da área houve aumento do fator CP. Para a maior parte da área este período foi marcado pela consolidação de áreas com elevados valores de fator $\mathrm{CP}$ especialmente para os ambientes de solos menos propícios à agricultura e, portanto, destinados ao uso por pastagem.

A análise da dinâmica dos valores do fator $\mathrm{CP}$ entre 2005 e 2014 revelou uma redução dos valores de fator $\mathrm{CP}$ em cerca de $2,92 \%$ da área. $\mathrm{O}$ uso por agricultura $(2,3 \%)$ em áreas que antes eram de solo exposto e pastagem contribuiu para essa pequena redução. Neste contexto, vale destacar o cultivo de eucalipto em áreas fortemente afetadas por processos erosivos, especialmente na alta bacia do rio Araguaia. Já em relação às áreas nas quais houve aumento do fator CP percebe-se uma acentuada redução em relação aos períodos anteriores. De 2005 a 2014 apenas $7 \%$ da área passou por processo de conversão para uso antrópico, conforme observado nas cores amarelo e laranja (parte $\boldsymbol{a}$ da Figura 9).

Por último, a Figura $9 \mathrm{~b}$ sintetiza o processo de conversão da cobertura vegetal em uso antrópico e o consequente aumento de áreas com elevados valores do fator CP. Neste contexto merecem destaques as áreas que passaram por aumento dos valores e, principalmente, aquelas cujos valores de fator CP já eram elevados em 1985 e que continuavam na mesma condição em 2014. A Figura 10 sintetiza quantitativamente a relação bivariada dos fatores CP de 1985 e 2014 e respectivos percentuais de focos e área de contribuição erosiva. Nesta relação nota-se que as classes de maior fator $\mathrm{CP}$ em 2014 respondem pela maior parte das feições e área de contribuição erosiva. Esse percentual é mais elevado quando relacionado com as classes de elevado fator CP de 1985. 
Figura 9 - Mapas de mudanças no fator CP entre 2005 e 2014 e respectivas áreas de ocorrência (a); entre 1985 e 2014 (b).
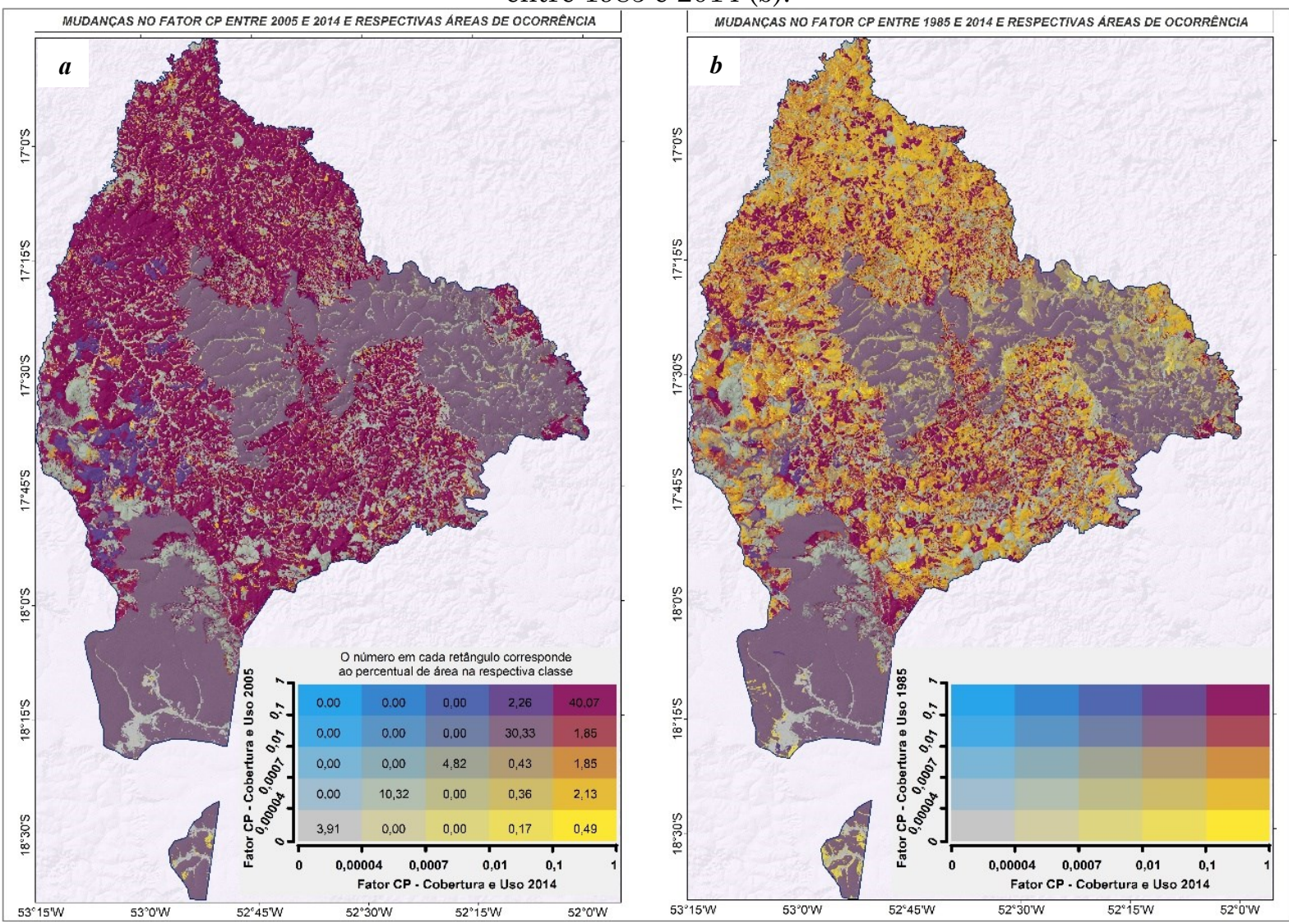

Fonte: Os autores (2018).

Figura 10 - Distribuição de área entre as classes de fator CP de 1985 e 2014 e respectivos percentuais de focos e área de contribuição erosiva.

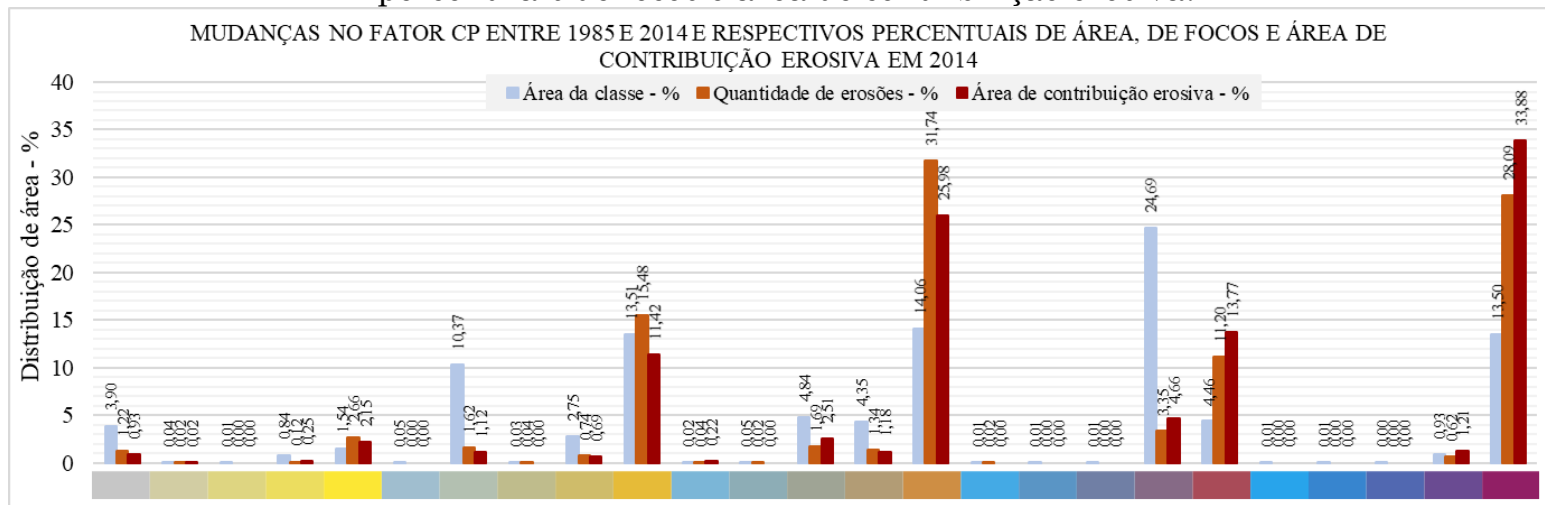

Fonte: Os autores (2018).

Diante do processo de antropização já constatado nos períodos anteriores, o grande destaque no período 2005-2014 é o elevado percentual de áreas na condição de solo exposto e principalmente pastagem. Assim, é importante destacar que esse elevado percentual se deve ao efeito cumulativo verificado por meio das áreas que tiveram aumento do fator CP no período 1985-1995 e 1995-2005.

\section{CONCLUSÕES}

A análise permitiu verificar que a degradação por processos erosivos é contemporânea do processo de expansão de áreas de pastagens nas áreas adjacentes às áreas de planaltos onde teve início a agricultura na década de 1960 e consolidada nas décadas de 1970 e 1980. A expansão para terrenos menos planos e menos favoráveis foi determinante para o processo de degradação. 
A permanência de áreas pouco favoráveis à agricultura na condição de solos exposto e principalmente por pastagens por longos períodos se mostrou determinante para a ocorrência de situações críticas de degradação. As áreas com maior densidade de focos, bem como maior área de contribuição erosiva, ocorrem em ambientes nos quais predominou o uso por solo exposto e pastagem ao longo de todo o recorte temporal analisado.

Em relação à preferência do processo de desmatamento ressalta-se que o mesmo se deu para a fitofisionomia Cerradão, relacionada aos terrenos planos e solos argilosos dos topos de planaltos. Já o desmatamento e consequente maior degradação por processos erosivos se deu para as fitofisionomias predominantes em terrenos de maior declividade e solos com textura variando de média a arenosa. Dentre elas se destacam o Cerrado Típico, o Cerrado Denso e o Cerrado Ralo, cujo processo de conversão resultou em ambientes com estágios avançados de degradação.

\section{AGRADECIMENTOS}

Os autores agradecem à Comissão de Aperfeiçoamento de Pessoal de Nível Superior (CAPES) pela concessão da bolsa de doutorado do primeiro autor, e ao Conselho Nacional de Desenvolvimento Científico e Tecnológico (CNPq) pela concessão da Bolsa de Produtividade do segundo autor.

\section{FINANCIAMENTO}

Comissão de Aperfeiçoamento de Pessoal de Nível Superior (CAPES).

\section{REFERÊNCIAS}

AB'SABER, A. N.; COSTA JÚNIOR, M. Contribuição ao estudo do Sudoeste Goiano. Boletim Paulista de Geografia, São Paulo, v. 2 , n. 4, p. 3-26, 1950. Disponível em: https://www.agb.org.br/publicacoes/index.php/ boletim-paulista/article/view/1402/1260.

Acesso em: 25 de março de 2020.

ALVES, W. S. et al. Análise da fragilidade ambiental da bacia do ribeirão das Abóboras, em Rio Verde, Sudoeste de Goiás. Revista Internacional de Ciencia y Tecnologia de
La Información Geográfica, n. 19, p. 81108, 2017. http://dx.doi.org/10.21138/GF.556. ARNOUS, M. O.; EL-RAYES, A. E.; HELMY, A. M. Land-use/land-cover change: a key to understanding land degradation and relating environmental impacts in Northwestern Sinai, Egypt. Environ Earth Science, v. 7, n. 76, p. 263-283, 2017. http://dx.doi.org/10.1007/s12665-017-6571-3.

BARBALHO, M. G. S.; CASTRO, S. S. Compartimentação morfopedológica como subsídio ao planejamento do uso da terra das bacias dos rios Claro e dos Bois, Estado de Goiás. Fronteiras: Journal of Social, Technological and Environmental Science, v.3, n.2, p. 111-131, 2014. http://dx.doi.org/10.21664/2238-

8869.2014v3i2.p111-131.

BAJOCCO, S. A. et al. The impact of land use/land cover changes on land degradation dynamics: A Mediterranean case study. Environmental Management, v. 49, n. 5, p. 978-989, 2012. http://dx.doi.org/10.1007/s00267-012-9831-8.

BRASIL, RADAMBRASIL, Projeto. Folha SE.22 Goiânia: geologia, geomorfologia, pedologia, vegetação, uso potencial da terra. Rio de Janeiro: FIBGE, 1983. (Levantamento de recursos naturais, v. 31), $764 \mathrm{p}$.

BORGES, R. E. Complexos agroindustriais e desenvolvimento regional: $\mathrm{O}$ caso do sudoeste de Goiás. In: Encontro Nacional de Geografia Agrária, 21, Territórios em disputa: os desafios da Geografia Agrária nas contradições do desenvolvimento brasileiro, 2012, Uberlândia. Anais... Uberlândia: UFU, 2012. Disponível em: http://www.lagea.ig.ufu.br/xx1enga/anais_eng a_2012/gts/1217_1.pdf. Acessado em: 09 de junho de 2020.

CAPITANI, C. et al. From local scenarios to national maps: a participatory framework for envisioning the future of Tanzania. Ecology and Society, v. 21, n. 3. p. 1-33, 2016. http://dx.doi.org/10.5751/ES-08565-210304.

CASTRO, B. L. G. Identificação de fitofisionomias do bioma Cerrado no estado de Goiás, por meio de aerogamaespectrometria e sensoriamento remoto. 2014. 210 p. Tese (Doutorado em Geociências Aplicadas) Instituto de Geociências, Universidade de Brasília, Brasília, 2014.

DRAGO, V. A. et al. Contribuição ao estudo geológico do vale do Rio Araguaia. In: Simpósio de Geologia do Centro-Oeste, 1, 1981, Goiânia. Ata...Goiânia: SBG, 1981, p. 
404-421.

ELLIS, E. C. Ecology in an anthropogenic Biosphere. Ecological Monographs, v. 85, n. 3, p. 287-331, 2015. https://doi.org/10.1890/142274.1.

FINDELL, A. K. et al. The impact of anthropogenic land use and land cover change on regional climate extremes. Nature Communications. v. 8, n. 989, p. 1-10, 2017. https://doi.org/10.1038/s41467-017-01038-w.

GRIGGS, D. M. et al. An integrated framework for sustainable development goals. Ecology and Society, v. 19, n. 4, p. 1-24. 2014. http://dx.doi.org/10.5751/ES-07082-190449.

HASSAN, Z. et al. Dynamics of land use and land cover change (LULCC) using geospatial techniques: a case study of Islamabad Pakistan. SpringerPlus, v. 5, n. 812, p. 1-11, 2016. http://dx.doi.org/10.1186/s40064-0162414-z.

GRAZIANO DA SILVA, J. Do complexo rural aos complexos agroindustriais. In: GRAZIANO DA SILVA, J. A nova dinâmica da agricultura brasileira, $2^{a}$ ed., Campinas: Instituto de Economia - UNICAMP, 1996. 217 p.

LACERDA FILHO, J. V. de; FRASCA, A. A. S. Compartimentação geotectônica. In: MOREIRA, M. L. O. et al. (Org.). Geologia do Estado de Goiás e do Distrito Federal. Goiânia: CPRM/SIC-FUNMINERAL, 2008. 143 p.

MENEZES, B. B. et al. Uso e ocupação agropecuária no cerrado brasileiro: transformações da paisagem e seus impactos ambientais no Estado de Goiás. In: Encontro de Geógrafos da América Latina, 12, 2009, Montevideo. Anais...Montevideo: 12 EGAL, 2009. Disponível em: http://observatoriogeograficoamericalatina.org .mx/egal12/Procesosambientales/Impactoambi ental/26.pdf. Acessado em: 12 de setembro de 2020.

MONTEIRO, C. A. F. Notas para o estudo do clima do Centro-Oeste brasileiro. Revista Brasileira de Geografia, v. 13, n. 1, 1951. p. 3 - $46 . \quad$ Disponível em: https://biblioteca.ibge.gov.br/visualizacao/peri odicos/115/rbg_1951_v13_n1.pdf. Acesso em 22 de junho de 2020.

MOREIRA, M. L. O. et al. Geologia do Estado de Goiás e do Distrito Federal. Goiânia: CPRM/SIC-FUNMINERAL, 2008. 143 p.

NIMER, E. Climatologia da Região CentroOeste do Brasil. Revista Brasileira de Geografia, ano 34, n. 4, p. 3-30, 1972. Disponível em: https://biblioteca.ibge.gov.br/visualizacao/peri odicos/115/rbg_1972_v34_n4.pdf. Acesso em 22 de junho de 2020.

NUNES, E.D. Modelagem de processos erosivos hídricos lineares no município de mineiros - GO. 2015. 242 p. Tese (Doutorado em Geografia), Instituto de Estudos Socioambientais, Universidade Federal de Goiás, Goiânia, 2015.

NUNES, E. D.; CASTRO, S. S. Compartimentação morfopedológica aplicada à distribuição de padrões espaciais de processos erosivos em solos frágeis - Município de Mineiros, GO. In: CASTRO, S. S.; HERNANI, L. C. (Orgs.). Solos Frágeis: Caracterização, manejo e sustentabilidade. Brasília, DF: Embrapa, 2015, p. 293-324.

OLIVEIRA, A. R. et al. A ocupação do Cerrado goiano pelo agronegócio canavieiro. Revista NERA, ano 21, n. 43, p. 79-100, 2018. https://doi.org/10.47946/rnera.v0i43.5525.

OLIVEIRA, I. J. Chapadões descerrados: relações entre vegetação, relevo, e uso das terras em Goiás. Boletim Goiano de Geografia, v. 34, n. 2, p. 311-336, 2014. https://doi.org/10.5216/bgg.v34i2.31734.

OLIVEIRA, J. S. Avaliação de modelos de elevação na estimativa de perda de solos em ambiente SIG. 2012. 103 p. Dissertação (Mestrado em Agronomia) - Escola Superior de Agricultura Luiz de Queiroz - Universidade de São Paulo, Piracicaba, 2012.

ÖZŞAHIN, E.; UYGUR, V. The effects of land use and land cover changes (LULCC) in Kuseyr plateu of Turkey on erosion. Turkish Journal of Agriculture and Forestry, v. 38, p. 478-487, 2014. https://doi.org/10.3906/tar1306-86.

ÖZŞAHIN, E. et al. Land use and land cover changes (LULCC), a key to understand soil erosion intensities in the Maritsa Basin. Water v. $10, \quad$ n. $3,2018$. https://doi.org/10.3390/w10030335.

PAULINO, H. B. et al. Atributos Bioquímicos do Solo Sob Diferentes Sistemas de Produção no Sudoeste Goiano. Global Science and Technology, v. 8, n. 2, p. 74-86, 2015. https://doi.org/10.14688/1984-

3801/gst.v8n2p74-86.

PINTO, H. E.; WANDER, A. E. A formação econômica do Sudoeste Goiano e suas implicações à luz da teoria dos custos de transação. Revista Eletrônica de Economia da Universidade Estadual de Goiás, v. 12, n. 02, p. 29-41, 2016. Disponível em:

https://www.revista.ueg.br/index.php/economi a/article/view/5034. Acesso em: 15 de outubro 
de 2019.

RIBEIRO, J. F.; WALTER, B. M. T. As principais fitofisionomias do bioma Cerrado. In: SANO, S. M.; ALMEIDA, S. P.; RIBEIRO, J. F. (Edit.). Cerrado: ecologia e flora. Brasília: Embrapa Informação Tecnológica, 2008. Cap. 6, p.151-212.

ROCHA, M. D. et al. II PND, o POLOCENTRO e o desenvolvimento do Estado de Goiás. UNINCOR- Revista da Universidade Vale do Rio Verde, v. 12, n. 1, p. 682-692, 2014. http://dx.doi.org/10.5892/ruvrd.v12i1.1459.g12 08.

SCOPEL, I.; SOUSA, M.; MARTINS, A. P. Infiltração de água e potencial de uso de solos muito arenosos nos Cerrados (Savanas) do Brasil. Boletim Goiano de Geografia, Goiânia, v. $33, \quad$ n. $2, \quad 2013, \quad$ p. $45-61$. https://doi.org/10.5216/bgg.v33i2.25556.

SILVA, R. B. M. et al. Relação solo/vegetação em ambiente de cerrado sobre influência do Grupo Urucuia. Ciência Florestal, v. 25, n. 2, p. 363 $-$ 373 , 2015. https://doi.org/10.5902/1980509818455.

SILVA, C. M. Entre Fênix e Ceres: a grande aceleração e a fronteira agrícola no Cerrado. Varia História, v. 34, n. 65, 409-444, 2018. http://dx.doi.org/10.1590/010487752018000200006.
SILVA, S. C. da; SANTANA, N. M. P. de; PELEGRINI, J. C. Caracterização climática do Estado de Goiás. Goiânia: Secretaria de Indústria e Comércio, Superintendência de Geologia e Mineração, 2006. 133 p.

STEIN, D. P.; DONZELLI, P.; GIMENEZ, A.F.; PONÇANO, W.L.; LOMBARDI NETO, F. Potencial de erosão laminar natural e antrópica na bacia do Peixe-Paranapanema. In: Simpósio Nacional de Controle de Erosão, 4, Marília, 1987. Anais, Marília, p. 105-135.

\section{CONTRIBUIÇÃO DOS AUTORES}

Elizon Dias Nunes idealizou a proposta de estudos e foi responsável pelo mapeamento das feições erosivas hídricas lineares, das classes de cobertura e condições de uso do solo, bem como o tratamento dos dados e elaboração cartográfica. Selma Simões de castro foi responsável pela orientação do artigo, bem como sua revisão inicial. Os dois autores aturam em conjunto nos trabalhos de campo no sudoeste goiano, bem como na redação do manuscrito. 